\title{
Psychological Cost, Religiusitas, Love of Money dan Kepatuhan Wajib Pajak Badan Sektor UMKM
}

\author{
Ni Kadek Rahayu Artharini ${ }^{1}$ \\ Fakultas Ekonomi dan Bisnis \\ Universitas Udayana, Indonesia
}

\author{
Naniek Noviari ${ }^{2}$ \\ Fakultas Ekonomi dan Bisnis \\ Universitas Udayana, Indonesia
}

\begin{abstract}
Surel : artharini16@gmail.com
ABSTRAK

UMKM memainkan peran yang sangat penting dalam mendorong percepatan pertumbuhan ekonomi suatu negara. Penelitian ini bertujuan untuk mengetahui pengaruh psychological cost, religiusitas, dan love of money terhadap kepatuhan Wajib Pajak Badan sektor UMKM yang terdaftar di KPP Pratama Denpasar Timur. Insidental sampling digunakan sebagai metode penentuan sampel dan diperoleh sampel sebanyak 96 UMKM. Teknik analisis data yang digunakan adalah teknik analisis regresi linear berganda. Hasil penelitian menunjukkan bahwa psychological cost dan religiusitas berpengaruh positif terhadap kepatuhan Wajib Pajak Badan sektor UMKM, sedangkan love of money berpengaruh negatif terhadap kepatuhan Wajib Pajak Badan sektor UMKM.

Kata Kunci: Psychological Cost; Religiusitas; Love of Money; Kepatuhan WP.

\section{Psychological Cost, Religiosity, Love of Money and SME Sector Agency Taxpayer Compliance}

\section{ABSTRACT}

MSMEs play a very important role in encouraging the acceleration of a country's economic growth. This study aims to determine the effect of psychological cost, religiosity, and love of money on the taxpayer compliance of the MSMEs sector registered in the East Denpasar Tax Office. Incidental sampling is used as a method of determining the sample and obtained a sample of 96 MSMEs. The data analysis technique used is multiple linear regression analysis techniques. The results showed that psychological cost and religiosity had a positive effect on the compliance of the Taxpayers of the MSME sector, while love of money had a negative effect on the compliance of the Taxpayers of the MSMEs sector.

Keywords: $\quad$ Psychological Cost; Religiosity; Love of Money; Corporate Compliance Tax Payer's.

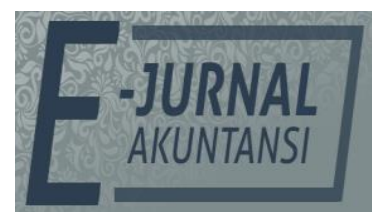

e-ISSN 2302-8556

Vol. 31 No. 5

Denpasar, Mei 2021

Hal. 1344-1355

DOI:

10.24843/EJA.2021.v31.i05.p20

PENGUTIPAN

Artharini, N.K.R., \& Noviari, N. (2021). Psychological Cost, Religiusitas, Love of Money dan Kepatuhan Wajib Pajak Badan Sektor UMKM. EJurnal Akuntansi, 31(5), 1344-

1355

RIWAYAT ARTIKEL:

Artikel Masuk:

17 Desember 2019

Artikel Diterima:

3 Maret 2020

Artikel dapat diakses : https://ojs.unud.ac.id/index.php/Akuntansi/index 


\section{PENDAHULUAN}

Penerimaan sektor pajak menjadi salah satu sumber pendanaan dalam pembangunan nasional. Mengingat sistem pemungutan pajak yang berlaku di Indonesia adalah Self Assesment System, maka Wajib Pajak (WP) diberikan kepercayaan untuk melakukan pendaftaran, perhitungan, dan pelaporan sendiri kewajiban perpajakan. Peran aktif masyarakat sebagai WP dalam memenuhi kewajiban perpajakan sangat diharapkan melalui penerapan sistem ini (Adhimatra \& Noviari, 2018), namun sistem ini memiliki kelemahan dimana segala risiko pajak yang mungkin timbul akan menjadi tanggungjawab WP (Mardiasmo, 2016).. Mengingat sifat pajak yang memaksa tetapi sistem pemungutan pajak yang berlaku di Indonesia adalah Self Assesment System, tentunya akan menimbulkan berbagai kesulitan bagi pemerintah dalam meningkatkan penerimaan dari sektor pajak.

Usaha Mikro, Kecil, dan Menengah (UMKM) memainkan peran yang sangat penting dalam mendorong percepatan pertumbuhan ekonomi suatu negara (Eragbhe \& Modugu, 2014). Banyaknya jumlah UMKM diharapkan mampu meningkatkan penerimaan dari sektor pajak. Upaya yang telah dilakukan pemerintah untuk meningkatkan kepatuhan pajak UMKM adalah dengan menurunkan tarif PPh final dari 1 persen menjadi 0,5 persen yang diatur dalam PP No. 23 Tahun 2018 tentang Pajak Penghasilan dari Usaha yang Diterima atau Diperoleh WP yang Memiliki Peredaran Bruto Tertentu. Penurunan tarif PPh final ini bertujuan agar WP yang penghasilan brutonya lebih rendah tetap mau membayar kewajiban perpajakan (Cahyani, 2019), namun masih banyak WP UMKM yang menjadikan pajak sebagai beban yang harus dihindari. Selain itu, banyak WP yang menganggap bahwa biaya yang harus dikeluarkan dalam proses pemenuhan kewajiban perpajakan jumlahnya cukup besar, sehingga WP cenderung enggan dalam membayar pajak (Adhimatra \& Noviari, 2018).

Salah satu daerah di Bali sebagai penyumbang pajak sektor UMKM adalah Kota Denpasar. Kota Denpasar memiliki 31.826 UMKM yang tersebar di 4 (empat) kecamatan, yaitu Kecamatan Denpasar Utara, Denpasar Selatan, Denpasar Timur, dan Denpasar Barat. Jumlah UMKM Badan terbanyak berjumlah 2.083 unit yang merupakan gabungan UMKM Badan yang ada di Kecamatan Denpasar Timur dan Kecamatan Denpasar Selatan dan merupakan wilayah kerja Kantor Pelayanan Pajak (KPP) Pratama Denpasar Timur. Salah satu masalah yang harus diperhatikan oleh pembuat dan pengamat kebijakan ekonomi adalah bagaimana meningkatkan kepatuhan WP. Kepatuhan pajak adalah keadaan WP yang memenuhi semua kewajiban dan hak perpajakannya (Dewi et.al., 2017). Melihat jumlah UMKM badan yang ada di Kecamatan Denpasar Timur dan Kecamatan Denpasar Selatan merupakan paling banyak dibandingkan dengan daerah Kecamatan Denpasar Barat dan Kecamatan Denpasar Utara, tentunya perlu untuk diteliti bagaimana kepatuhan dari WP Badan sektor UMKM. Adapun tingkat kepatuhan WP Badan Sektor UMKM yang terdaftar di KPP Pratama Denpasar Timur dapat dilihat pada Tabel 1.

Pada Tabel 1, ditunjukkan bahwa selama tahun 2015-2018 jumlah WP Badan meningkat setiap tahunnya mulai dari 1.477, 1.538, 1587, dan 2.083, 
namun yang melaporkan SPT Tahunan selalu lebih rendah jumlahnya dari WP yang terdaftar. Selain itu, tingkat kepatuhan WP yang terdaftar di KPP Pratama Denpasar Timur cenderung fluktuatif.

Tabel 1. Kepatuhan WP Badan Sektor UMKM yang terdaftar di KPP Pratama Denpasar Timur tahun 2015-2018

\begin{tabular}{|c|c|c|c|c|}
\hline Uraian & $\begin{array}{l}2015 \\
\text { (Unit) }\end{array}$ & $\begin{array}{l}2016 \\
\text { (Unit) }\end{array}$ & $\begin{array}{l}2017 \\
\text { (Unit) }\end{array}$ & $\begin{array}{l}2018 \\
\text { (Unit) }\end{array}$ \\
\hline Jumlah WP Badan UMKM & 1.477 & 1.538 & 1.587 & 2.083 \\
\hline $\begin{array}{l}\text { Jumlah WP Badan UMKM yg } \\
\text { melapor SPT Tahunan }\end{array}$ & 1.288 & 873 & 1.379 & 1.433 \\
\hline Persentase Kepatuhan & $87 \%$ & $57 \%$ & $87 \%$ & $69 \%$ \\
\hline
\end{tabular}

Sumber: Data Penelitian, 2019

Psychological cost atau biaya psikologis menjadi salah satu faktor yang dapat memengaruhi kepatuhan WP (Lopes \& Martins, 2013). Psychological cost merupakan salah satu komponen dari biaya kepatuhan yang meliputi ketidakpuasan, kecemasan, dan keresahan yang dialami oleh WP dalam serangkaian kegiatan pemenuhan kewajiban perpajakannya (Kurniawati \& Toly, 2014). Faktor lain yang dapat memengaruhi kepatuhan WP adalah religiusitas yang merupakan salah satu faktor non-ekonomi (Ermawati, 2018). Tingkat kepatuhan WP dapat dipengaruhi oleh dua faktor, yaitu faktor ekonomi dan non-ekonomi (Mohdali, 2013). Faktor lain yang dapat memengaruhi tingkat kepatuhan WP yaitu love of money (Salim, 2018). Love of money adalah sikap cinta terhadap uang yang dimiliki oleh setiap individu dalam mencapai titik kesuksesannya (Mitayani, 2019). Konsep love of money ini digunakan untuk memperkirakan perasaan subjektif seseorang terhadap uang (Wijaya, 2016). Sikap kecintaan terhadap uang yang tinggi dapat memicu seseorang dalam melakukan tindakan tidak etis, seperti tidak memenuhi kewajiban perpajakan.

Berdasarkan hasil penelitian terdahulu, peneliti ingin meneliti kembali kepatuhan WP menggunakan tiga variabel bebas, yaitu psychological cost, religiusitas, dan love of money yang dilakukan di KPP Pratama Denpasar Timur. Tujuan penelitian ini adalah untuk memperoleh bukti empiris adanya pengaruh psychological cost, religiusitas, dan love of money terhadap kepatuhan WP Badan sektor UMKM di KPP Pratama Denpasar Timur.

Berdasarkan Theory of Planned Behavior yaitu komponen control beliefs, WP dalam mengambil keputusan atas suatu perilaku telah mempertimbangkan berbagai aspek dan konsekuensi yang akan diterimanya, namun ketika pertimbangan tersebut tidak tepat, maka WP akan meyakini bahwa hal tersebut dapat menjadi penghambat dalam memenuhi kewajiban perpajakan (control beliefs). Biaya psikologis berupa perasaan cemas, stress, frustasi, serta resah akan muncul dan dirasakan oleh WP ketika harus berhadapan dengan otoritas pajak ataupun menghadapi masalah yang ditimbulkan oleh sistem dan peraturan perpajakan yang berlaku. Semakin tinggi biaya psikologis maka WP akan mempertimbangkan kembali dan memilih untuk berperilaku patuh agar tidak terkena dampak berupa sanksi perpajakan atas tindakan yang dilakukan selama proses pemenuhan kewajiban perpajakan. Hal ini akan membuat keinginan WP dalam memenuhi kewajiban perpajakan semakin tinggi. Persepsi WP terkait seberapa kuat rasa cemas, stress, dan frustasi mampu mendukung perilaku WP 
untuk taat pajak akan memengaruhi tingkat kepatuhan WP tersebut. Hasil penelitian yang dilakukan oleh Lopes \& Martins (2013) menyatakan bahwa biaya psikologis yang tinggi dapat meningkatkan keinginan WP untuk berperilaku patuh dengan menghubungkan sikap dan perilaku dari WP. Hasil penelitian serupa yang dilakukan oleh Chebusit et al., (2014) menyatakan bahwa biaya psikologis berpengaruh positif terhadap kepatuhan pajak di Kenya. Hasil penelitian sejalan yang dilakukan oleh Jayawardane (2015) menemukan hasil bahwa biaya psikologis berpengaruh positif terhadap kepatuhan pajak.

$\mathrm{H}_{1}$ : Psychological cost berpengaruh positif terhadap kepatuhan WP Badan.

Berdasarkan Theory of Planned Behaviour, religiusitas dalam penelitian ini berkaitan dengan normative beliefs. Ketika seorang individu memiliki keyakinan bahwa nilai-nilai keagamaan yang dimiliki mampu menuntun menuju kesejahteraan hidup, maka akan menimbulkan perilaku yang positif. Setiap WP tentunya memiliki religiusitas yang dijadikan sebagai pedoman menjalani kehidupan, termasuk dalam melaksanakan kewajiban perpajakannya. Dengan adanya peran dari religiusitas diharapkan dapat memicu perilaku positif dan mencegah perilaku negatif terhadap kepatuhan perpajakan melalui keyakinan agama yang kuat, sehingga akan mendorong WP untuk bersikap patuh dalam memenuhi kewajiban perpajakan. Penelitian yang dilakukan oleh Pope \& Mohdali (2010) menemukan hasil bahwa religiusitas berpengaruh positif terhadap kepatuhan pajak. Penelitian yang dilakukan oleh Ali (2013) juga menemukan hasil bahwa religiusitas berpengaruh positif terhadap kepatuhan WP sukarela. Penelitian serupa yang dilakukan oleh Benk et al., (2016) juga menemukan hasil bahwa religiusitas berpengaruh positif dan signifikan terhadap sikap patuh WP.

$\mathrm{H}_{2}$ : Religiusitas berpengaruh positif terhadap kepatuhan WP Badan sektor UMKM.

Berdasarkan Theory of Planned Behaviour, yaitu komponen behavioral beliefs, seseorang akan memiliki keyakinan bahwa dengan memiliki banyak uang akan mencapai kesejahteraan hidup sehingga cenderung memutuskan untuk tidak mau mengeluarkan uang apabila tidak mendapat imbal balik secara langsung. Seorang WP yang memiliki love of money yang tinggi cenderung tidak mau membayar kewajiban perpajakan apabila tidak mendapat imbal balik secara langsung atas sejumlah uang yang dikeluarkan dalam memenuhi kewajiban perpajakan. Penelitian yang dilakukan oleh Elias \& Farag (2010) menyatakan bahwa love of money memiliki pengaruh negatif terhadap kepatuhan WP. Hasil penelitian sejalan yang dilakukan oleh Salim (2018) menyatakan bahwa sikap love of money berpengaruh negatif terhadap kepatuhan pajak.

$\mathrm{H}_{2}$ : Love of Money berpengaruh negatif terhadap kepatuhan WP Badan sektor $\mathrm{UMKM}$

\section{METODE PENELITIAN}

Lokasi penelitian dilakukan di KPP Pratama Denpasar Timur. Alasan pemilihan lokasi ini karena di KPP Pratama Denpasar Timur tingkat kepatuhan WP Badan sektor UMKM cenderung fluktuatif. Variabel terikat dalam penelitian ini adalah kepatuhan WP Badan sektor UMKM, sedangkan variabel bebas dalam penelitian 
ini adalah psychological cost, religiusitas, dan love of money.Definisi operasional variabel dalam penelitian ini dijelaskan pada Tabel 2.

Tabel 2. Rangkuman Definisi Operasional Variabel

\begin{tabular}{|c|c|c|c|}
\hline Variabel & Definisi & Indikator & Referensi \\
\hline $\begin{array}{l}\text { Kepatuhan } \\
\text { WP Badan } \\
\text { sektor } \\
\text { UMKM } \\
(Y)\end{array}$ & $\begin{array}{l}\text { Suatu keadaan } \\
\text { dimana WP telah } \\
\text { memenuhi kewajiban } \\
\text { dan hak perpajakan }\end{array}$ & $\begin{array}{l}\text { Kepatuhan WP dalam } \\
\text { mendaftarkan diri } \\
\text { Benar dalam perhitungan pajak } \\
\text { terhutang } \\
\text { Membayar pajak terhutang tepat } \\
\text { waktu } \\
\text { Melaporkan SPT tepat waktu } \\
\text { Bersedia membayar tunggakan } \\
\text { dan denda administrasi }\end{array}$ & $\begin{array}{l}\text { Febrianti } \\
(2014)\end{array}$ \\
\hline $\begin{array}{l}\text { Psychological } \\
\text { Cost } \\
\left(\mathrm{X}_{1}\right)\end{array}$ & $\begin{array}{l}\text { Rasa frustasi, cemas, } \\
\text { stress WP ketika } \\
\text { berhadapan dengan } \\
\text { urusan perpajakan }\end{array}$ & $\begin{array}{l}\text { Keadaan pikiran saat pengisian } \\
\text { SPT yang kompleks } \\
\text { Tekanan saat berhadapan } \\
\text { dengan otoritas pajak } \\
\text { Tekanan saat berhadapan } \\
\text { dengan sistem perpajakan yang } \\
\text { kompleks } \\
\text { Kekhawatiran saat terlibat dalam } \\
\text { proses pemenuhan kewajiban } \\
\text { perpajakan }\end{array}$ & $\begin{array}{l}\text { Lopes \& } \\
\text { Martins } \\
\text { (2013) }\end{array}$ \\
\hline $\begin{array}{l}\text { Religiusitas } \\
\left(\mathrm{X}_{2}\right)\end{array}$ & $\begin{array}{lr}\text { Nilai-nilai } & \\
\text { keagamaan } & \text { luhur } \\
\text { dari Tuhan } & \text { yang } \\
\text { mengajarkan } & \\
\text { kejujuran } & \text { dan } \\
\text { integritas } & \end{array}$ & $\begin{array}{l}\text { Keyakinan } \\
\text { Pengalaman } \\
\text { Penghayatan } \\
\text { Pengetahuan }\end{array}$ & $\begin{array}{l}\text { Salsabila } \\
\text { (2018) }\end{array}$ \\
\hline $\begin{array}{l}\text { Love of money } \\
\left(\mathrm{X}_{3}\right)\end{array}$ & $\begin{array}{l}\text { Sikap cinta terhadap } \\
\text { uang }\end{array}$ & $\begin{array}{l}\text { Good } \\
\text { Achievement } \\
\text { Self-esteem } \\
\text { Budget } \\
\text { Freedom }\end{array}$ & $\begin{array}{l}\text { Hafizhah } \\
\text { (2016) }\end{array}$ \\
\hline
\end{tabular}

Sumber: Data Penelitian, 2019

Populasi dalam penelitian ini adalah seluruh WP Badan UMKM yang terdaftar di KPP Pratama Denpasar Timur tahun 2015 - 2018 yaitu berjumlah 2.083 UMKM. Sampel dalam penelitian adalah 96 WP Badan yang didapat dari perhitungan menggunakan rumus Slovin. Metode penentuan sampel yang digunakan dalam penelitian ini adalah metode Insidental Sampling, yang merupakan teknik penentuan sampel berdasarkan kebetulan. Adapun kriteria sampel yang cocok dijadikan sebagai sumber data, yaitu merupakan WP Badan sektor UMKM, NPWP terdaftar di KPP Pratama Denpasar Timur, dan memiliki jabatan minimal Staff Accounting pada UMKM bersangkutan. Metode pengumpulan data yang digunakan dalam penelitian ini adalah kuesioner. Masing-masing pernyataan dalam kuesioner diberikan skor 1-4 berdasarkan skala likert 4 poin. Jenis data yang digunakan dalam penelitian ini adalah data kuantitatif yang meliputi hasil jawaban responden atas kuesioner, data kepatuhan WP Badan sektor UMKM yang terdaftar di KPP Pratama Denpasar Timur tahun 2015-2018, dan data jumlah UMKM yang ada di Kota Denpasar 
tahun 2015-2018, sedangkan jenis data kualitatif dalam penelitian ini meliputi data-data mengenai responden yang digunakan dalam penelitian ini, yaitu jabatan responden, NPWP terdaftar di KPP Pratama Denpasar Timur, dan perusahaan termasuk sektor UMKM.

Sumber data yang digunakan dalam penelitian ini adalah data primer dan sekunder. Data primer dalam penelian ini adalah hasil jawaban responden atas pernyataan yang ada dalam kuesioner, sedangkan data sekunder dalam penelitian ini adalah data kepatuhan WP Badan Sektor UMKM yang terdaftar di KPP Pratama Denpasar Timur tahun 2015-2018 dan data jumlah UMKM yang ada di Kota Denpasar tahun 2015-2018. Teknik analisis data yang digunakan dalam penelitian ini Analisis Regresi Linear Berganda yang meliputi Uji Kelayakan Model (Uji F), Uji Koefisien Determinasi $\left(R^{2}\right)$, dan Uji Hipotesis (Uji t). Adapun persamaan regresi yang digunakan dalam penelitian ini menggunakan model, sebagai berikut.

$Y=\alpha+\beta_{1} X_{1}+\beta_{2} X_{2}+\beta_{3} X_{3}+\varepsilon$

Keterangan :

$\begin{array}{ll}\mathrm{K} & =\text { Kepatuhan WP }(\mathrm{Y}) \\ \mathrm{a} & =\text { Konstanta } \\ \beta 1-3 & =\text { Koefisien Regresi } \\ \mathrm{X} 1 & =\text { Psychological Cost } \\ \mathrm{X} 2 & =\text { Religiusitas } \\ \mathrm{X} 3 & =\text { Love of Money } \\ \varepsilon & =\text { Standard Error }\end{array}$

HASIL DAN PEMBAHASAN

Karakteristik responden dalam penelitian ini dapat dilihat pada Tabel 3.

Tabel 3. Karakteristisk Responden

\begin{tabular}{|c|c|c|}
\hline Karakteristik Responden & Frekuensi & Persentase \\
\hline \multicolumn{3}{|l|}{ Berdasarkan Jabatan } \\
\hline Staff Accounting & 83 & $86,46 \%$ \\
\hline Manager & 13 & $13,54 \%$ \\
\hline Jumlah & 96 & $100 \%$ \\
\hline \multicolumn{3}{|l|}{ Berdasarkan NPWP terdaftar di KPP Pratama } \\
\hline Denpasar Timur & & \\
\hline Ya & 96 & $100 \%$ \\
\hline Tidak & 0 & 0 \\
\hline Jumlah & 96 & $100 \%$ \\
\hline $\begin{array}{l}\text { Berdasarkan perusahaan termasuk sektor } \\
\text { UMKM }\end{array}$ & & \\
\hline Ya & 96 & $100 \%$ \\
\hline Tidak & 0 & 0 \\
\hline Jumlah & 96 & $100 \%$ \\
\hline
\end{tabular}

Sumber: Data Penelitian, 2019

Pada Tabel 3, ditunjukkan bahwa responden dengan jabatan sebagai Staff Accounting berjumlah 83 dengan persentase 86,46 persen dan yang memiliki jabatan sebagai Manager berjumlah 13 dengan persentase 13,54\%. Responden yang memiliki NPWP terdaftar di KPP Pratama Denpasar Timur dan termasuk 
perusahaan sektor UMKM berjumlah 96 responden dengan persentase 100 persen.

Statistik deskriptif adalah uji yang digunakan untuk melihat nilai minimum, nilai maksimum, nilai rata-rata, dan standar deviasi dari masingmasing variabel. Hasil statistik deskriptif dalam penelitian ini dapat dilihat pada Tabel 4.

Tabel 4. Hasil Statistik Deskriptif

\begin{tabular}{llllll}
\hline Variabel & N & Min. & Max. & Mean & Std. Deviasi \\
\hline Psychological Cost & 96 & 10,00 & 16,00 & 13,44 & 1,716 \\
Religiusitas & 96 & 10,00 & 20,00 & 16,23 & 2,110 \\
Love Of Money & 96 & 13,00 & 24,00 & 20,36 & 2,411 \\
Kepatuhan WP & 96 & 14,00 & 20,00 & 16,89 & 1,897 \\
\hline
\end{tabular}

Sumber: Data Penelitian, 2019

Berdasarkan Tabel 4, dapat dilihat bahwa variabel psychological cost memiliki nilai minimum sebesar 10,00 , nilai maksimum sebesar 16,00 , nilai ratarata sebesar 13,44, dan standar deviasi sebesar 1,716 yang memiliki makna dimana terjadi penyimpangan nilai psychological cost pada nilai rata-ratanya sebesar 1,716. Variabel religiusitas memiliki nilai minimum sebesar 10,00, nilai maksimum sebesar 20,00, nilai rata-rata sebesar 16,23, dan standar deviasi sebesar 2,110 yang memiliki makna dimana terjadi penyimpangan nilai religiusitas pada nilai rata-ratanya sebesar 2,110. Variabel love of money memiliki nilai minimum sebesar 13,00, nilai maksimum sebesar 24,00, nilai rata-rata sebesar 20,36, dan standar deviasi sebesar 2,411 yang memiliki makna dimana terjadi penyimpangan nilai love of money pada nilai rata-ratanya sebesar 2,411. Variabel kepatuhan WP memiliki nilai minimum sebesar 14,00, nilai maksimum sebesar 20,00, nilai rata-rata sebesar 16,89, dan standar deviasi sebesar 1,897 yang memiliki makna dimana terjadi penyimpangan nilai kepatuhan WP pada nilai rata-ratanya sebesar 1,897.

Uji Analisis Regresi Linear Berganda digunakan untuk mengetahui pengaruh dua atau lebih variabel independen pada variabel dependen. Hasil uji regresi linear berganda dapat dilihat pada Tabel 5.

Tabel 5. Hasil Uji Analisis Regresi Linear Berganda

\begin{tabular}{lllll}
\hline Variabel & $\begin{array}{l}\text { Unstandardized } \\
\text { Beta }\end{array}$ & $\begin{array}{l}\text { Std. } \\
\text { Error }\end{array}$ & t hitung & Sig. \\
\hline (Constant) & 11,785 & 2,419 & 4,872 & 0,000 \\
Psychological Cost & 0,213 & 0,103 & 2,072 & 0,041 \\
Religiusitas & 0,331 & 0,084 & 3,957 & 0,000 \\
Love of Money & $-0,153$ & 0,070 & $-2,186$ & 0,031 \\
\hline
\end{tabular}

Sumber: Data Penelitian, 2019 berikut:

Berdasarkan Tabel 5, dapat dibuat model persamaan regresi sebagai

$$
\mathrm{Y}=11,785+0,213 \mathrm{X}_{1}+0,331 \mathrm{X}_{2}-0,153 \mathrm{X}_{3}+\varepsilon
$$

Nilai konstanta ( $\alpha$ ) sebesar 11,785 memiliki arti bahwa apabila nilai psychological cost (X1), religiusitas (X2), dan love of money (X3) bernilai 0 (nol), maka nilai kepatuhan WP (Y) adalah sebesar 11,785. Nilai koefisien psychological cost (X1) yaitu 0,213 memiliki arti bahwa psychological cost memiliki hubungan positif terhadap kepatuhan WP, apabila psychological cost (X1) meningkat sebesar satu satuan maka kepatuhan WP (Y) akan meningkat sebesar 0,213 satuan 
dengan asumsi variabel bebas lainnya konstan. Nilai koefisien religiusitas (X2) yaitu sebesar 0,331 memiliki arti bahwa religiusitas memiliki hubungan positif terhadap kepatuhan WP, apabila religiusitas (X2) meningkat sebesar satu satuan, maka kepatuhan WP (Y) akan meningkat sebesar 0,331 satuan dengan asumsi variabel bebas lainnya konstan. Nilai koefisien love of money (X3) yaitu sebesar 0,153 memiliki arti bahwa love of money memiliki hubungan negatif terhadap kepatuhan WP, apabila love of money (X3) meningkat sebesar satu satuan, maka kepatuhan WP (Y) akan menurun sebesar 0,153 satuan dengan asumsi variabel bebas lainnya konstan.

Hasil Uji Kelayakan Model (Uji F) bertujuan untuk mengetahui apakah semua variabel bebas yang diidentifikasi tepat digunakan untuk memprediksi kepatuhan WP. Hasil Uji F dapat dilihat pada Tabel 6.

Tabel 6. Hasil Uji Kelayakan Model (Uji F)

\begin{tabular}{clllll}
\hline Model & Sum of Squares & df & Mean Square $\mathrm{F}$ & Sig. \\
\hline Regression & 65,160 & 3 & 21,720 & 7,310 & 0,000 \\
Residual & 273,340 & 92 & 2,971 & & \\
Total & 338,500 & 95 & & & \\
\hline
\end{tabular}

Sumber: Data Penelitian, 2019

Berdasarkan Tabel 6, dapat dilihat bahwa nilai $F_{\text {hitung }}$ sebesar 7,310 dengan signifikansi sebesar 0,000 $<0,05$ sehingga dapat disimpulkan bahwa model regresi yang dibuat layak digunakan untuk menjelaskan pengaruh pschological cost, religiusitas, dan love of money terhadap kepatuhan WP Badan sektor UMKM.

Uji Koefisien Determinasi mengukur seberapa jauh kemampuan variansi variabel independen dalam menerangkan variansi variabel dependen. Hasil Uji Koefisien Determinasi dapat dilihat pada Tabel 7.

Tabel 7. Hasil Uji Koefisien Determinasi $\left(\mathbf{R}^{2}\right)$

\begin{tabular}{lllll}
\hline Model & $\mathrm{R}$ & R Square & Adjusted R Square & Std. Error of the Estimate \\
\hline 1 & 0,439 & 0,192 & 0,166 & 1,724
\end{tabular}

Sumber: Data Penelitian, 2019

Berdasarkan Tabel 7, dapat dilihat bahwa nilai dari adjusted $\mathrm{R}$ Square adalah sebesar 0,166 atau 16,6 persen yang berarti 16,6 persen variansi kepatuhan WP Badan sektor UMKM dipengaruhi oleh variansi psychological cost, religiusitas, dan love of money, sisanya sebesar 83,4 persen dipengaruhi oleh variabel-variabel lain yang tidak dijelaskan dalam penelitian ini.

Pengujian hipotesi (Uji t) dilakukan untuk menunjukkan pengaruh semua variabel independen secara parsial pada variabel dependen. Hasil Uji $t$ dapat dilihat pada Tabel 8.

Tabel 8. Hasil Uji Hipotesis (Uji t)

\begin{tabular}{lll}
\hline Variabel & t hitung & Sig. \\
\hline (Constant) & 4,872 & 0,000 \\
Psychological Cost & 2,072 & 0,041 \\
Religiusitas & 3,957 & 0,000 \\
Love of Money & $-2,186$ & 0,031 \\
\hline
\end{tabular}

Sumber: Data Penelitian, 2019

Berdasarkan Tabel 8, psychological cost memiliki nilai signifikansi sebesar 0,041 dengan $t_{h i t u n g}$ bernilai positif sebesar 2,072. Nilai signifikansi sebesar 0,041< 0,05 yang mengindikasikan bahwa $\mathrm{H}_{0}$ ditolak dan $\mathrm{H}_{1}$ diterima. Hal ini berarti, 
secara parsial psychological cost berpengaruh positif terhadap kepatuhan WP Badan sektor UMKM. Religiusitas memiliki nilai signifikansi sebesar 0,000 dengan $t_{\text {hitung }}$ bernilai positif sebesar 3,957. Nilai signifikansi sebesar 0,000 $<0,05$ yang mengindikasikan bahwa $\mathrm{H}_{0}$ ditolak dan $\mathrm{H}_{1}$ diterima. Hal ini berarti, secara parsial religiusitas berpengaruh positif terhadap kepatuhan WP Badan sektor UMKM. Love of money memiliki nilai signifikansi sebesar 0,031 dengan $t_{\text {hitung }}$ bernilai negatif sebesar -2,186. Nilai signifikansi sebesar 0,031 $<0,05$ yang mengindikasikan bahwa $\mathrm{H}_{0}$ ditolak dan $\mathrm{H}_{1}$ diterima. Hal ini berarti, secara parsial love of money berpengaruh negatif terhadap kepatuhan WP Badan sektor UMKM.

Berdasarkan pembahasan yang telah diuraikan terdapat beberapa implikasi. Berkaitan dengan implikasi teoritis, peneliti menemukan hasil mengenai bagaimana pengaruh psychological cost, religiusitas, dan love of money terhadap kepatuhan WP Badan sektor UMKM di KPP Pratama Denpasar Timur, yang menyatakan bahwa psychological cost dan religiusitas berpengaruh positif terhadap kepatuhan WP, sedangkan love of money berpengaruh negatif terhadap kepatuhan WP. Penelitian ini mendukung Theory of Planned Behaviour yaitu kepatuhan WP akan dipengaruhi oleh niat WP itu sendiri dalam mengambil tindakan untuk patuh ataupun tidak patuh terhadap kewajiban perpajakan.

Berkaitan dengan implikasi praktis, penelitian ini memberikan manfaat secara langsung maupun tidak langsung pada pihak-pihak yang berkepentingan. Bagi KPP Pratama Denpasar Timur penelitian ini diharapkan dapat memberi masukan yang berharga dan dapat menjadi salah satu bahan evaluasi untuk meningkatkan kepatuhan WP. Bagi pihak lain penelitian ini diharapkan dapat menjadi bahan pertimbangan dan referensi bagi peneliti selanjutnya yang tertarik untuk meneliti kajian yang sama di waktu yang akan datang.

\section{SIMPULAN}

Berdasarkan analisis dan pembahasan hasil penelitian yang telah diuraikan maka dapat disimpulkan bahwa psychological cost berpengaruh positif terhadap kepatuhan WP Badan sektor UMKM, religiusitas berpengaruh positif terhadap kepatuhan WP Badan sektor UMKM, dan love of money berpengaruh negatif terhadap kepatuhan WP sektor UMKM. Berdasarkan hasil penelitian dan simpulan, saran-saran yang ingin disampaikan kepada peneliti-peneliti selanjutnya terkait dengan Koefisien Determinasi (Adjusted $R^{2}$ ) penelitian ini sebesar 0,166 yang berarti bahwa 16,6 persen variansi kepatuhan WP Badan dipengaruhi oleh variansi variabel bebas yang ada dalam penelitian ini, dan sisanya sebesar 83,4 persen dipengaruhi oleh variabel lain di luar model penelitian ini, sehingga penelitian selanjutnya dapat menambahkan variabel lain terutama faktor-faktor yang dapat memengaruhi kepatuhan WP Badan sektor UMKM. Hal ini diperuntukkan agar hasil dari penelitian selanjutnya dapat digunakan secara lebih luas.

\section{REFERENSI}

Adhimatra, A. A. G. W., \& Noviari, N. (2018). Faktor Yang Memengaruhi Kepatuhan WP Orang Pribadi Pada Kantor Pelayanan Pajak Pratama Denpasar Timur. E-Jurnal Akuntansi Universitas Udayana, 25, 717-744. 
Ajzen, I. (2011). The Theory Of Planned Behaviour: Reactions And Reflections. Psychology And Health. Https:/ / Doi.Org/10.1080/08870446.2011.613995

Alfisyah, K. D., \& Anwar, M. K. (2018). Pengaruh Religiusitas Terhadap Kinerja Karyawan Muslim Kantor Pusat Pt Perkebunan Nusantara Xi. Jurnal Ekonomi Islam, 1(2), 99-107. Https://Doi.Org/Https://Jurnalmahasiswa.Unesa.Ac.Id/Index.Php/Jei / Article/View/24058

Ali, N. R. M. (2013). The Influence Of Religiosity On Taxpayers' Compliance Attitudes. (Unpublished Doctoral Thesis), Curtin University. (March). Https:/ / Doi.Org/10.1108/Arj-08-2013-0061

Andhika Utama Dan Dudi. (2016). Pengaruh Religiusitas Terhadap Perilaku Kepatuhan WP Orang Pribadi Di Provinsi Dki Jakarta. Jurnal Lingkar Widyaiswara, Edisi. 3 N(2), 1-13. Https://Doi.Org/10.1016/S00404020(00)00446-4

Basri, Y. M. (2015). Pengaruh Gender, Religiusitas Dan Sikap Love Of Money Pada Persepsi Etika Penggelapan Pajak Mahasiswa Akuntasi. Jurnal Ilmiah Akuntansi Dan Bisnis, 45-54.

Benk, S., Budak, T., Yüzba, B., \& Mohdali, R. (2016). The Impact Of Religiosity On Tax Compliance Among Turkish Self-Employed Taxpayers. Religions, 7(4), 1-10. Https://Doi.Org/10.3390/Rel7040037

Chebusit, C., Namusonge, G. S., Biraori, O. E., \& Kipkoech, E. C. (2014). Factors Affecting Tax Compliance Among Small And Medium Enterprises In Kitale. International Journal Of Recent Research In Commerce Economics And Management (Ijrrcem), 1(3), 60-75.

Daniel, A., Akowe, A., \& Awaje, A. (2016). Tax Compliance Behaviour Of Small Scale Enterprises In Bassa Local Government Area Of Kogi State. Journal Of Good Governance And Sustainable Development In Africa (Jggsda), 3(1), 5872. Retrieved From Http://Www.Rcmss.Com.

Devos, K. (2009). An Investigation Into Australian Personal Tax Evaders- Their Attitudes Towards Compliance And The Penalties For Non-Compliance An Investigation Into Australian Personal Tax Evaders- Their Attitudes. Revenue Law Journal, 19(1), Article 2.

Dewi, L. R. K., Sulindawati, N. L. G. E., \& Sinarwati, N. K. (2017). Pengaruh Sikap Rasional Dan Lingkungan WP Terhadap Kepatuhan Pajak Dengan Preferensi Risiko Sebagai Variabel Moderasi (Studi Kasus Pada WP Orang Pribadi Yang Terdaftar Di Kpp Pratama Singaraja). E-Journal S1 Ak Universitas Pendidikan Ganesha, 7(1), 1-11.

Elias, R. Z., \& Farag, M. (2010). The Relationship Between Accounting Students' Love Of Money And Their Ethical Perception. Managerial Auditing Journal. Https:/ / Doi.Org/10.1108/02686901011026369

Eragbhe, E., \& Modugu, K. P. (2014). Tax Compliance Costs Of Small And Medium Scale Enterprises In Nigeria. International Journal Of Accounting And Taxation, 2(1), 63-87. Retrieved From Www.Aripd.Org/Ijat

Ermawati, N. (2018). Pengaruh Religiusitas, Kesadaran WP Dan Pengetahuan Perpajakan Terhadap Kepatuhan WP. Jurnal Akuntansi Universitas Muria Kudus. (2018), 106-122. 
Evans, C. (2008). Taxation Compliance And Administrative Costs: An Overview. Research Gate, (August), 447-468.

Ghouri, A. M., Khan, N. R., \& Abdul Kareem, O. B. (2016). Improving Employees Behavior Through Extension In Theory Of Planned Behavior: A Theoretical Perspective For Smes. International Journal Of Business And Management, 11(11), 196. Https://Doi.Org/10.5539/Ijbm.V11n11p196

Gitaru, K. (2017). Tax Effect Of Taxpayer Education On Tax Compliance In Kenya (A Case Study Of Sme's In Nairobi Central Business District). Munich Personal Repec Archive, (80344), 2-62.

Hafizhah, I. (2016). Faculty Of Economics Riau University, Pekanbaru Indonesia. Pengaruh Etika Uang Terhadap Kecuranagan Pajak Dengan Religiusitas, Gender Dan Materialisme Sebagai Variabel Moderasi, 2(2), 2010-2012.

Jayawardane, D. (2015). Psychological Factors Affect Tax Compliance - A Review Paper. International Journal Of Arts And Commerce, 4(6), 131-141.

Kibiwott, M. M. (2015). Determinants Of Tax Compliance Among Small And Medium. Governement Information Qaurtely, 27(11), 87-93. Https://Doi.Org/10.14738/Abr.35.1495.Citations

Kurniawati, M., \& Toly, A. A. (2014). Analisis Keadilan Pajak, Biaya Kepatuhan, Dan Tarif Pajak Terhadap Persepsi WP Mengenai Penggelapan Pajak Di Surabaya Barat. Tax E Accounting Review, 4(2), 1-12.

Lopes, C., \& Martins, A. (2013). The Psychological Costs Of Tax Compliance: Some Evidence From Portugal. Journal Of Applied Business And ..., 14(2), 53-61. Retrieved From Http://Www.NaBusinesspress.Com/Jabe/Lopes_Abstract.Html

Luh, N., Widia, P., \& Sari, A. (2019). Pengaruh Love Of Money , Equity Sensitivity, Dan Machiavellian Pada Persepsi Etis Mahasiswa Akuntansi Fakultas Ekonomi Dan Bisnis Universitas Udayana. E-Journal Akuntansi Fakultas Ekonomi Dan Bisnis, Universitas Udayana. 28, 1522-1549.

Mangoting, A. O. F. Dan Y. (2013). Pengaruh Kualitas Pelayanan Petugas Pajak, Sanksi Perpajakan Dan Biaya Kepatuhan Pajak Terhadap Kepatuhan WP Umkm. Tax \& Accounting Review, 1, 18-27.

Mitayani, Saras Putri. (2019). Pengaruh Pemahaman Perpajakan, Love Of Money, Religiusitas, Norma Subjektif, Dan Kemungkinan Terdeteksi Kecurangan Terhadap Persepsi WP Mengenai Etika Penggelapan Pajak (Tax Evasion) ( Studi Kasus Pada WP Orang Pribadi Yang Terdaftar Di Kantor Pelayanan Pajak Pratama Surakarta ). Tesis. Universitas Muhammadiyah.

Mohdali, R. (2011). The Influence Of Religiosity On Taxpayers' Compliance Attitudes: Empirical Evidence From A Mixed-Methods Study Raihana Mohdali 1.1-32.

Pope, J., \& Mohdali, R. (2010). The Role Of Religiosity In Tax Morale And Tax Compliance. Australian Tax Forum, 25(January 2010), 369-400.

Pratama, A. (2017). Machiavellianism, Perception On Tax Administration, Religiosity And Love Of Money Towards Tax Compliance: Exploratory Survey On Individual Taxpayers In Bandung City, Indonesia. International Journal Of Economics And Business Research. Https://Doi.Org/10.1504/Ijebr.2017.087521

Prof. Dr. Mardiasmo, Mba., A. (2016). Perpajakan Edisi Terbaru 2016. In Penerbit Andi. 
Putu, L., \& Cahyani, G. (2019). E-Jurnal Akuntansi Universitas Udayana Pengaruh Tarif Pajak, Pemahaman Perpajakan, Dan Sanksi Perpajakan Fakultas Ekonomi Dan Bisnis Universitas Udayana ( Unud ), Bali , Indonesia Pendahuluan Pajak Merupakan Salah Satu Target Utama Pemerintah Yang Dijad. E-Jurnal Akuntansi Universitas Udayana, 26, 18851911.

Rosianti, C., \& Mangoting, Y. (2014). Pengaruh Money Ethics Terhadap Tax Evasion Dengan Intrinsic Dan Extrinsic Religiosity Sebagai Variabel Moderating. Petra Christian University Tax And Accounting Review, 4(1), 111.

Salim, I. (2018). The Influence Of Perception Of Tax System And Love Of Money Toward Tax Compliance On Individual Taxpayer In Kpp Pratama Tanah Abang Jakarta. Tesis. President University

Salsabila, najla ulfah. (2018). Pengaruh religiusitas, nasionalisme, kepercayaan pada otoritas, dan tax amnesty terhadap kepatuhan WP orang pribadi. Skripsi.Yogyakarta:FE Universitas Islam Indonesia. Retrieved from https://dspace.uii.ac.id/bitstream/handle/123456789/7167/Skripsi Najla Ulfah Salsabila 14312175.pdf?sequence $=1$

Tang, T. L. P., \& Liu, H. (2012). Love of Money and Unethical Behavior Intention: Does an Authentic Supervisor's Personal Integrity and Character (ASPIRE) Make a Difference? Journal of Business Ethics. https://doi.org/10.1007/s10551-011-1040-5

Wijaya, T. A. (2016). Analisis Pengaruh Paham Machiavellianisme dan Aspek Love of Money terhadap Persepsi Etis Mahasiswa Akuntansi Tingkat Akhir di Kota Semarang. UDINUS, Fik, 1(1), 1-2. https://doi.org/10.1021/jf901375e

Worthington, E. L., Wade, N. G., Hight, T. L., Ripley, J. S., McCullough, M. E., Berry, J. W., ... O'Connor, L. (2003). The Religious Commitment Inventory-10: Development, refinement, and validation of a brief scale for research and counseling. Journal of Counseling Psychology. https://doi.org/10.1037/0022-0167.50.1.84 